\title{
Merger signals shift in xenotransplantation research
}

Xenotransplantation research in the United Kingdom is facing its second major setback this year. Following the August announcement that the Roslin Institute in Edinburgh is to cease work on its transgenic pig line amid concerns that pig viruses can infect human cells, the Swedish pharmaceutical company Novartis, has indicated its intention to close its Cambridge-based subsidiary, Imutran, by 31 December and merge its xeno research with the American company BioTransplant. The merger will create a new company to be named when it begins operating on 1 January, 2001.

Whereas Novartis has focused on immunosuppressive drug regimens as a means of increasing pig organ transplant survival, Imutran has developed a herd of genetically modified pigs whose organs express the human complement inhibitor human decay-accelerating factor (hDAF), which prevents destruction of the transplanted organ by the recipient's complement system. A combination of these techniques has resulted in an average transplant survival time of 39 days for baboons with a life-supporting pig heart.

However, for the past two years, Imutran has been seemingly unable to push its technology beyond this time point. This obstacle, combined with renewed concerns that porcine endogenous retroviruses may infect human cells (Nature 407, 90; 2000), seems to have driven Novartis to secure an alternative research strategy.

Boston-based BioTransplant has bred miniature swine for potential organ donation that are free from endogenous pig viruses. In addition, the company is exploring the technique of tolerance induction-a process of 're-educating' the immune system of the recipient to accept a donor organ without rejection. Preclinical studies in this area have involved the antibody elimination of mature $T$ cells in mice that recognize pig tissue as foreign, and subsequent transplantation of pig thymus tissue into mice so that new $T$ cells passing through the thymus tissue are taught to recognize pig antigens as 'self'. Mice treated in this way do not reject transplanted pig skin.

David Sachs of the Transplantation Biology Research Center at Massachusetts General Hospital told
Nature Medicine that he was "extremely pleased" to learn that the companies will be merging their technologies. "People have now realized that this problem is more difficult than first thought. Additional methods such as tolerance induction are needed because the amount of immunosuppressive drugs re quired for a xenotransplant will be so great that the side effects will be prohibitive," Sachs.

Yet another technique that will advance research is the development of alpha-galactosidase-knockout pigswhich lack the galactose alpha(1-3)galactose xenoantigen against which antibodies are produced. This

may become possible, says

Sachs, now that pig cloning techniques have been developed (Nature 407, 86; 2000).

BioTransplant's chief scientific officer, Julia Greenstein, who will head up the new company, told Nature Medicine that the group has begun pigto-monkey tolerance stud-

ies. "Since both we and Novartis can achieve a mean of 30 days with immunosuppressants, we're starting with the goal of 90 days. With the tolerance induction program, we're hoping to withdraw the immunosuppression. This will be tested with the miniature swine as well as the transgenic pigs that [Imutran] has."

Establishing proof-of-principle for the tolerance-induction protocol in a pigto-primate model is essential for the new company's continued support from Novartis, which will own two-thirds of the new venture and will finance it to the amount of $\$ 30$ million for the first three years. The goal is to be ready for clinical testing by the end of this period. Novartis supported Imutran for four years before pulling the plug.

Closure of the Imutran facilities will mean 70 job losses. Some senior executives have al ready secured positions in the new company. Henck Shuurmann will direct research, Corinne Saville of Imutran and Elliot Lebowitz will be members of the board of directors. David White, research director at Imutran, will move to Canada to take up the Calvin Stiller Xenotransplantation
Research Chair at the University of Western Ontario (UWO), housed within the Robarts Institute. This position, funded by Novartis to a value of US\$1 million, has been vacant for the two years since its establishment. White, who was understood to be keen to push forward with clinical trials of the hDAF transgenic organs, will be able to continue his research at UWO, which has developed an hDAF program based on pigs imported from Imutran.

In its final weeks, Imutran has become the object of adverse publicity in the UK. The animal advocacy group Uncaged Campaigns claims to have obtained in-

ternal company documents detailing pig-to-primate experiments carried out at Huntingdon Life Science Laboratories that reveal technical failures in pig-to-baboon experiments and show that animals suffered during the procedure. The situation was reported in a national newspaper, The Daily is taking legal action against Uncaged, claiming breech of confidentiality and copyright of the documents.

Meanwhile, Alan Coleman, research director of PPL Therapeutics-the UK's remaining commercial player in the field-says that the decision by Novartis to transfer support to BioTransplant shows that the company believes strongly that xenotransplantation will work: "If they had withdrawn from the arena then that would have been bad for the field. However, it is sad that they're transferring their investment to the US from the UK."

PPL is investigating a strategy similar to that of Imutran: the overexpression of the porcine equivalent of hDAF in transgenic pigs as a means of preventing complement destruction of the transplanted organ. The company has also established a pig cloning technique. Coleman believes that PPL could take the lead in xenotransplantation research, as Novartis' shift in strategy means that it will have to take time out to re-start its efforts within the new company and re-engineer a new pig herd.

Karen Birmingham, London 